\title{
Numerical Solution of Three-Dimensional Flow over Angled Backward-Facing Step with Raised Upper Wall
}

\author{
S. Bayraktar \\ Yildiz Technical University, Department of Naval Architecture \& Marine Engineering, Istanbul, 34349, Turkey \\ Email:sbay@yildiz.edu.tr
}

(Received July 23, 2013; accepted September 6, 2013)

\begin{abstract}
In the present study, results obtained from three-dimensional incompressible flow over backward-facing step in a rectangular duct using Realizable $\mathrm{k}-\varepsilon$ turbulence model are reported. Effects of step inclination angle have been investigated for $\beta=30^{\circ}, 45^{\circ}, 90^{\circ}$ while upper wall of duct kept parallel to the bottom wall and then rose to $\alpha=6^{\circ}$. Reynolds number based on freestream velocity and step height is examined by varying its magnitude in the range of 15,000-64,000. Simulated results are presented for revealing the general flow features and reattachment lengths after a successful validation of the present work with the experimental data of Driver and Seegmiller (1985). It is found that turbulence kinetic energy increases suddenly after the step for both straight and raised upper walls and reaches its maximum at $\mathrm{x} / \mathrm{h}=5$ that consistent with the published literature. The size of reattachment lengths increases with the step inclination angle, i.e., maximum reattachment length occurs at $90^{\circ}$ for both straight and raised upper walls. It is seen that raising the upper wall leads to longer reattachment lengths.
\end{abstract}

Keywords: Backward-facing step, Turbulent flow, Computational fluid dynamics, Reynolds-Averaged Navier-Stokes.

NOMENCLATURE

$\begin{array}{ll}\mathrm{AR} & \text { aspect ratio } \\ \mathrm{C}_{2} & \text { constant } \\ \mathrm{C}_{1 \varepsilon} & \text { constant } \\ \mathrm{C}_{\mu} & \text { constant (=0.09) } \\ \mathrm{DNS} & \text { Direct Numerical Simulation } \\ \mathrm{ER} & \text { expansion ratio } \\ \mathrm{G}_{\mathrm{k}} & \text { generation of turbulence kinetic energy due to the mean } \\ & \text { velocity gradients } \\ \mathrm{h} & \text { step height } \\ \mathrm{H} & \text { duct height } \\ \mathrm{k} & \text { turbulence kinetic energy } \\ \mathrm{l} & \text { turbulence length scale } \\ \mathrm{L} & \text { duct length } \\ \mathrm{LES} & \text { Large Eddy Simulation } \\ \mathrm{N} & \text { number of mesh elements } \\ \mathrm{P} & \text { pressure } \\ \mathrm{RANS} & \text { Reynolds-Averaged Navier-Stokes } \\ \mathrm{Re} & \text { Reynolds number } \\ \mathrm{S} & \text { modulus of the mean rate-of-strain tensor } \\ \mathrm{S}_{\mathrm{k}}, \mathrm{S}_{\varepsilon} & \text { source terms } \\ \mathrm{u} & \text { x-velocity component } \\ \mathrm{v} & \text { y-velocity component }\end{array}$
w z-velocity component
W duct width
$\mathrm{x} \quad$ streamwise direction
$\mathrm{X}_{\mathrm{R}}$ reattachment length
y vertical direction
$\mathrm{Z}$ spanwise direction
2D two-dimensional
3D three-dimensional

Greek Alpabet
$\alpha \quad$ upper wall inclination angle
$\beta \quad$ step inclination angle
$\delta \quad$ Kronecker delta
$\varepsilon \quad$ turbulence kinetic energy
dissipation rate
$\mu_{\mathrm{t}} \quad$ turbulence viscosity
$\rho$ density of the fluid
$\Sigma$ total
$\sigma_{\mathrm{k}} \quad$ turbulent Prandtl number for $\mathrm{k}$
$\sigma_{\varepsilon} \quad$ turbulent Prandtl number for $\varepsilon$

Symbols

$\infty$ freestream 


\section{INTRODUCTION}

Flow separation and reattachment that are caused by a sudden change in geometry occur in many engineering applications and devices such as pieces of electronic cooling equipment, cooling of nuclear reactors and turbine blades, flow in combustion chambers and in vertical plates with ribs, in wide angle diffusers and valves, heat exchangers, ducts and orifices, design situations such as stall on wings, and cavitation in pumps (Spazzini et al., 2001, Saldana et al., 2007).

Among this type of flows, the backward-facing step is one of the most investigated for understanding the effects of separation resulting from abrupt changes of geometry in an open flow setting. As the flow over backward facing-step cases shows all the essential features of separated flows the geometry is common in engineering applications as given above and has been used for benchmarking studies (Blackburn et al., 2008). Although its geometry is very simple, the flow physics is complex and still remains unclear. Therefore, many works have been done to investigate the effect of several parameters such as step height, Re number, Prandtl number, step inclination angle, expansion ratio (channel height downstream of the step to the channel height upstream of the step), aspect ratio (width of the model divided by the step height), temperature difference between the heated wall and the freestream, and buoyancy force on the flow and thermal fields downstream of the step (AbuMulaweh, 2003).

Vast ranges of works have been done by means of experimental techniques (Ruck and Makiola, 1993, So et al., 1993, Yoshioka et al., 2001, Abu-Mulaweh et al., 2002, Bouda et al., 2008, Terhaar et al., 2010) and numerical approaches (Barton, 1997, Chiang et al., 1999, Cruchaga, 1998, Lan et al., 2009). It was reported that the flow could be assumed 2D especially at large AR, therefore, some researchers worked on 2D domains. Rouizi et al. (2009) analyzed model reduction on a $2 \mathrm{D}$ numerical reduction model and good agreement was reported between published experimental and computational results for $\mathrm{Re}$ numbers from 150 to 750 . Using 2D simulations Chen et al. (2006) investigated step height for different $\mathrm{ER}$ at $\mathrm{Re}=28,000$. Lanzerstorfer and Kuhlmann (2012) analyzed linear stability of the 2D flow for different ER. Mehrez et al. (2010) and Bouterra et al. (2011) used Large Eddy Simulation (LES) to study the effects of a periodic perturbation on a $2 \mathrm{D}$ working domain.

Owing to the rapid developments in highperformance computing, 3D computational works have been done so far to analyze aforementioned parameters (Le et al., 1997; Barkley et al., 2002; Schafer et al., 2009; and Rajabi and Kavianpour, 2012). Among them flow separation and reattachment length is the most investigated subject due to its importance. Flow separation can be defined as a region of recirculating flow adjacent to boundaries. The positions for the reattachment of the separation regions are delimited by zero vorticity near the boundaries. Within the separation region the flow is characterized by recirculating vortices and flow reversals. Flow separation occurs in the flows with adverse pressure gradient (Williams and Baker, 1997). Stefano et al. (1998) calculated reattachment length for $2 \mathrm{D}$ and $3 \mathrm{D}$ inflow conditions for $\mathrm{Re}<900$. It was shown that reattachment values are very close to each other for small Re numbers. Lan et al. (2009) performed a $2 \mathrm{D}$ simulation for $\mathrm{ER}=1.48$ at different $\mathrm{Re}$ numbers to investigate reattachment length variation. Armaly et al. (1983) reported that the flow is laminar for $\operatorname{Re}<1,200$, the transitional $(1,200<\operatorname{Re}<6,600)$ where a sharp decrease in the reattachment length, a continued gradual, but irregular decrease to a minimum value at a $\mathrm{Re}$ number of approximately 5,500, then an increase to a constant level that characterizes the turbulent flow regime. The flow is fully turbulent when $\operatorname{Re}>6,600$.

Whereas the $90^{\circ}$ step geometry has often been investigated extensively in the past, the flow over the inclined step has attracted less attention except Ahn et al. (1997), Chen et al. (2006), Singh et al. (2011), Ruck and Makiola (1993). Although the phenomena of flow separation of internal flows caused by sudden changes in geometries such as flow over backwardfacing step is well-known, the flow over inclined backward facing step with raised upper wall has not been studied yet and therefore, according to the author`s knowledge this is the first paper deals with both the raised upper wall and inclined backwardfacing step. On this purpose, it is aimed to reveal some basic flow characteristics of such flow configuration and reattachment length at different Re numbers for straight and raised upper wall.

The paper structure is as follows; Section 2 describes the computational set-up including geometry, mesh structure and mathematical equations. Section 3 shows validation and simulation results while Section 4 summarizes the main findings.

\section{COMPUTATIONAL SeT-UP}

In the present study, finite volume formulation of incompressible Navier-Stokes equations and staggered non-uniform Cartesian grids are employed. Details of the computational set-up are given below.

\subsection{Geometry of the Problem}

According to Brederode and Bradshaw (1972) the flow is primarily $2 \mathrm{D}$ away from the sidewalls for an AR greater than 10 in the case of an ER of 1.11 . According to Papadopoulos and Otugen (1995) AR independency of a reattachment length has been 
assured when AR is greater than about 10 in the case of an ER of 2. Therefore, in the literature, it is usually accepted that the flow can be assumed $2 \mathrm{D}$ if $\mathrm{AR}$ is greater than 10 regardless of ER and other flow properties. Since the AR at the present study is lower than 10 all simulations are performed on a 3D domain.

Notation used in the present work is as follows; $x$ is the main flow direction, $y$ the vertical and $z$ spanwise direction. The velocity components in $x, y$ and $z$ directions are $u, v$ and $w$, respectively. All variables are presented in non-dimensionalized form using step height, $h$, and the free stream velocity, $u_{\infty}$ for the normalization. Dimensions of working domain and Cartesian coordinate system that located at the bottom corner of the step are illustrated in Fig.1. Length, height and width of the duct is $L=180 \mathrm{~h}, H_{\text {inlet }}=8 \mathrm{~h}$, $H_{\text {outlet }}=9 \mathrm{~h}$ and $\mathrm{W}=4 \mathrm{~h}$, respectively. It should be noted that the width of the channel has been inspired from the work of Rajabi and Kavianpour (2012), Addad et al. (2003), and Piirto et al. (2002).

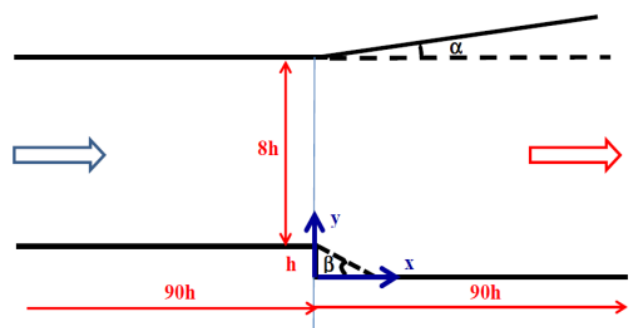

Fig. 1. Dimensions of the geometry (not to scale)

The inlet plane is located at $x=-90 h$ to let the flow to be fully developed while outlet is specified at $x=90 \mathrm{~h}$ prevent occurrence of backflow. It is suggested that the downstream length than $50 \mathrm{~h}$ does not change the flow behavior (Sheu and Rani, 2006). Therefore, the downstream length of $90 \mathrm{~h}$ is used for the present study. Above dimensions give $\mathrm{ER}$, and $\mathrm{AR}$ to be $\mathrm{ER}=1.12$ and $\mathrm{AR}=4$, respectively. The opposite wall of the step (upper wall) has been raised $6^{\circ}$ upward as done by Driver and Seegmiller (1985).

\subsection{Grid Structure}

The working domain has been discretized by structured non-uniform grids (Fig.2). Optimum grid resolutions have been obtained after systematic grid sensitivity tests.

Since the present work has been focused on the backward-facing step the grids in the vicinity of the step have been clustered towards the step from all directions. Four different meshes have been generated; coarse ( $\Sigma \mathrm{N}=518,500$ elements), normal $(\Sigma N=735,560 \quad$ elements $), \quad$ fine $\quad(\Sigma N=1,470,600$ elements) and finally the finest mesh $(\Sigma \mathrm{N}=2,094,960$ elements) as shown in Table 1.

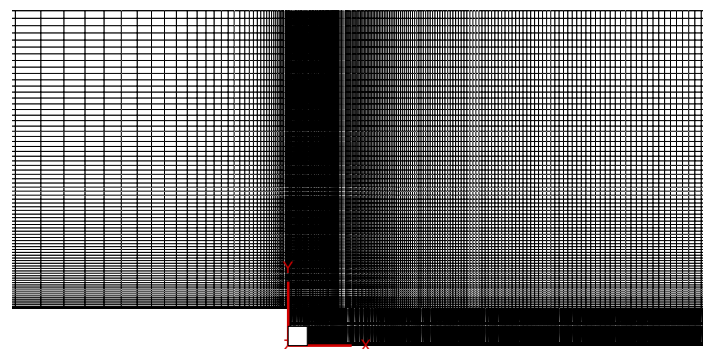

(a)

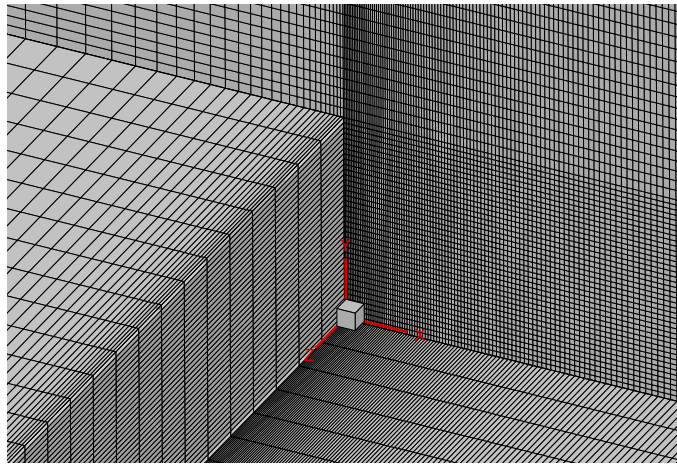

(b)

Fig. 2. Non-uniform structured mesh elements (a) and close-look of the mesh in the vicinity of the backwardfacing step (b)

Table 1 No of grid elements at x, y, z-directions

\begin{tabular}{|l|c|c|c|c|}
\hline Meshes & $\mathbf{N}_{\mathbf{x}}$ & $\mathbf{N}_{\mathbf{y}}$ & $\mathbf{N}_{\mathbf{z}}$ & $\mathbf{\Sigma} \mathbf{N}$ \\
\hline Coarse & 290 & 76 & 25 & 518,500 \\
\hline Normal & 325 & 86 & 28 & 735,560 \\
\hline Fine & 360 & 114 & 38 & $1,470,600$ \\
\hline Finest & 404 & 1128 & 43 & $2,094,960$ \\
\hline
\end{tabular}

Optimum grid number has been obtained by comparing dimensionless streamwise velocity component that normalized by free stream velocity. Since it gives the similar results normal mesh has been chosen for remaining simulations to get faster and economical solutions (Fig.3).

\subsection{Initial and Boundary Conditions}

Uniform freestream velocity profile has been applied to the upstream of the backward-facing step as inlet boundary condition. The upstream has been kept long enough to ensure developing turbulent velocity profile before the step. The development of velocity from uniform to turbulent profile has been shown in Fig.4 for evidence. As it can be seen from the stations before the step velocity shows turbulent character at $x / h=-20$, $-15,-10,-5$ and $x / h=0$. 


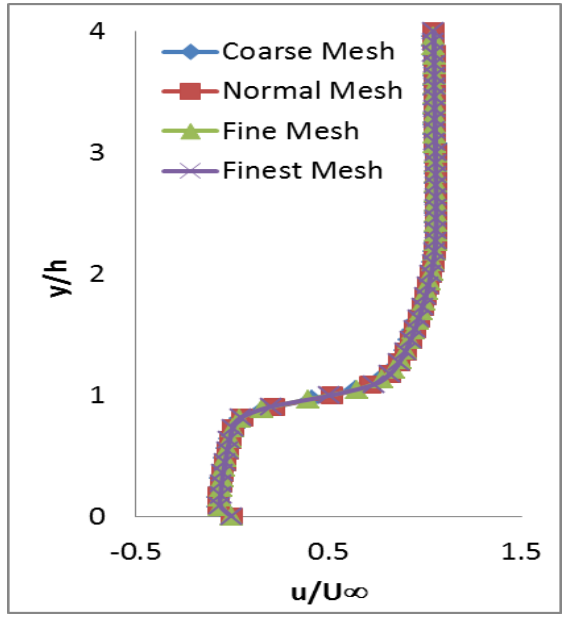

Fig. 3. Mesh independence study for four different mesh numbers, $\mathrm{x} / \mathrm{h}=1$

The downstream of the step $(x / h=90)$ has been specified as pressure outlet. Top and bottom surface of the duct has been assigned as wall type with noslip condition. Symmetry boundary condition has been applied to the right and left sides of the duct for faster and economical solution.

As initial boundary condition $\mathrm{u}=\mathrm{U}_{\infty}, \mathrm{v}=0$ have been used. Turbulence kinetic energy and its dissipation rate have been calculated according to Eq.1 and Eq.2 at the initialization step as proposed by $\operatorname{Kim}$ et al. (2005).

$k=0.002 u_{\infty}^{2}$

$\varepsilon=C_{\mu}^{3 / 4}\left(\frac{k^{3 / 2}}{l}\right)$

The freestream velocity of $44.2 \mathrm{~ms}^{-1}$ resulting Reynolds number $\operatorname{Re}_{\mathrm{h}}=38,000$ based on step height. Besides that effect of Re number of $15,000,22,000$, 47,000 and 64,000 have been investigated. According to Armaly et al. (1983) and Williams and Baker (1997) the flow is identified as laminar when $\operatorname{Re}<1,200$, as transitional for $1,200<\operatorname{Re}<6,600$, and as turbulent when $\operatorname{Re}>6,600$. Therefore, it can be noted that the flow of the present study is fully turbulent.

\subsection{Mathematical Background}

Turbulent flows require to be resolved all its length and time scales. In spite of today's computer development flows with high Re numbers and/or complex geometries at high Re numbers cannot be performed to resolve all length and time scales. Therefore, turbulence modeling is necessary to make reasonable predictions for those unresolved scales. Traditional approaches of computational studies area usually based on RANS equations where the turbulent spectrum is parameterized by semi-empirical turbulence modeling. Solving RANS equations enables researchers and scientists to get fast and economical solutions. Therefore, one can find many works carried out by RANS solution.

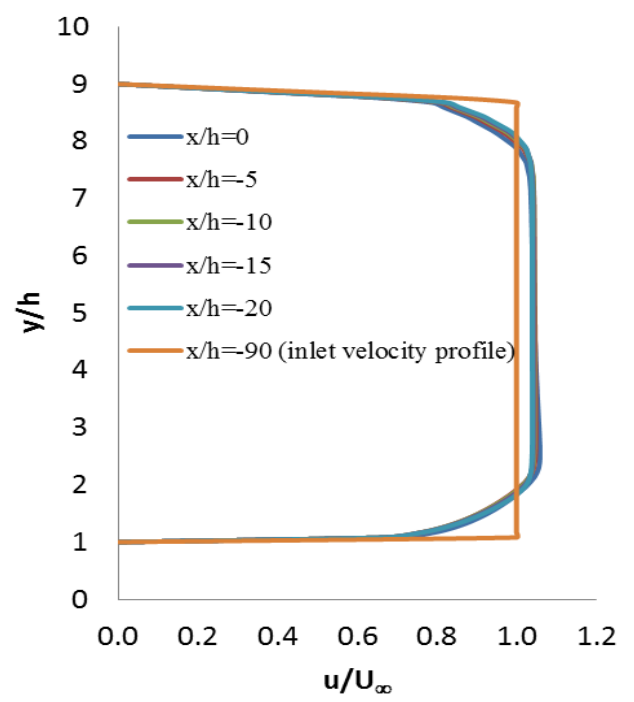

Fig. 4. Inlet velocity profile at inlet and subsequent stations

In spite of its advantages, there are so many shortcomings. For example, it was reported that the effect of large-scale vertical structures and distortion of turbulent eddies is not taken into account. This lack of solution leads researchers to use DNS in which Navier-Stokes equations are solved directly without any introducing any model. Due to that reason DNS consumes huge computer resources even for flows of moderately high Re numbers. LES offers the advantages of calculating directly the large-scale energy containing motion and modeling the smallscale energy dissipating motion. LES predictions require less computational time compared with DNS, less modeling errors compared with RANS, (Yu et al., 2004). In spite of its advantages LES of most of the engineering and industrial applications are not possible due to limitation of the computational resources. Therefore, most of the computational studies have been made by using RANS. Since the present study is performed by a personal lap-top AMD A4, $1.90 \mathrm{GHz}$ processor equipped with 4 GB RAM, it seems feasible to run simulations by employing RANS equations. Governing equations of steady, incompressible flow is given in Eq.3 and Eq.4 in general form. Realizable k- $\varepsilon$ turbulence model is used.

$\frac{\partial}{\partial x_{i}}\left(\rho u_{i}\right)=0$ 
$\frac{\partial}{\partial x_{j}}\left(\rho u_{i} u_{j}\right)=-\frac{\partial P}{\partial x_{i}}+$

$\frac{\partial}{\partial x_{j}}\left[\mu\left(\frac{\partial u_{i}}{\partial x_{j}}+\frac{\partial u_{j}}{\partial x_{i}}-\frac{2}{3} \delta_{i j} \frac{\partial u_{l}}{\partial x_{l}}\right)\right]$

$+\frac{\partial}{\partial x_{j}}\left(-\rho \overline{u_{i}^{\prime} u_{j}^{\prime}}\right)$

$-\rho \overline{u_{i}^{\prime} u_{j}^{\prime}}$ is the Reynolds stresses that must be modeled in order to close the Eq.4. A common method employs the Boussinesq hypothesis to relate the Reynolds stresses to the mean velocity gradients:

$$
-\rho \overline{u_{i}^{\prime} u_{j}^{\prime}}=\mu_{t}\left(\frac{\partial u_{i}}{\partial x_{j}}+\frac{\partial u_{j}}{\partial x_{i}}\right)-\frac{2}{3}\left(\rho k+\mu_{t} \frac{\partial u_{k}}{\partial x_{k}}\right) \delta_{i j}
$$

The advantage of the this approach is the relatively low computational cost associated with the computation of $\mu_{t}$. In Realizable k- $\varepsilon$ turbulence model $\mu_{t}$ is computed as a function of $k$ and $\varepsilon$. The modeled transport equations for $k$ and $\varepsilon$ in the Realizable k- $\varepsilon$ model are;

$$
\begin{aligned}
& \frac{\partial}{\partial t}(\rho k)+\frac{\partial}{\partial x_{j}}\left(\rho k u_{j}\right)= \\
& \frac{\partial}{\partial x_{j}}\left[\left(\mu+\frac{\mu_{t}}{\sigma_{k}}\right) \frac{\partial k}{\partial x_{j}}\right]+G_{k}-\rho \varepsilon
\end{aligned}
$$

and

$$
\begin{aligned}
& \frac{\partial}{\partial t}(\rho \varepsilon)+\frac{\partial}{\partial x_{j}}\left(\rho \varepsilon u_{j}\right)= \\
& \frac{\partial}{\partial x_{j}}\left[\left(\mu+\frac{\mu_{t}}{\sigma_{\varepsilon}}\right) \frac{\partial \varepsilon}{\partial x_{j}}\right]+\rho C_{1} S \varepsilon-\rho C_{2} \frac{\varepsilon^{2}}{k+\sqrt{v \varepsilon}}
\end{aligned}
$$

where

$$
\begin{aligned}
& C_{1}=\max \left[0.43, \frac{\eta}{\eta+5}\right] \\
& \eta=S \frac{k}{\varepsilon} \\
& \mathrm{G}_{\mathrm{k}} \text { calculated as }
\end{aligned}
$$

$G_{k}=-\rho \overline{u_{i}^{\prime} u_{j}^{\prime}} \frac{\partial u_{j}}{\partial x_{i}}$

To evaluate $G_{k}$ in a manner consistent with the Boussinesq hypothesis,

$G_{k}=\mu_{t} S^{2}$

$S=\sqrt{2 S_{i j} S_{i j}}$

The eddy viscosity is computed from

$\mu_{t}=\rho C_{\mu} \frac{k}{\varepsilon}$

In above equation $C_{\mu}$ is not constant and computed from

$C_{\mu}=\frac{1}{A_{0}+A_{s} \frac{k U^{*}}{\varepsilon}}$

where

$U^{*}=\sqrt{S_{i j} S_{i j}+\tilde{\Omega}_{i j} \tilde{\Omega}_{i j}}$

And $\tilde{\Omega}_{i j}=\overline{\Omega_{i j}}$ here $\overline{\Omega_{i j}}$ is the mean rate-of-rotation tensor viewed in a rotating reference frame with the angular velocity $\omega_{\mathrm{k}}$. Model constants $\mathrm{A}_{0}=4.04$ and $A_{s}=\sqrt{6} \cos \phi$ are given by where

$\phi=\frac{1}{3} \cos ^{-1}(\sqrt{6} W)$

$W=\frac{S_{i j} S_{j k} S_{k i}}{\tilde{S}^{3}}$

$\tilde{S}^{3}=\sqrt{S_{i j} S_{i j}}$

$S_{i j}=\frac{1}{2}\left(\frac{\partial u_{j}}{\partial x_{i}}+\frac{\partial u_{i}}{\partial x_{j}}\right)$

The model constants, $C_{2}=1.9 \quad \sigma_{k}=1.0 \quad \sigma_{\varepsilon}=1.2$ 


\subsection{Numerical Scheme}

Simulations have been performed by finite-volume method for numerically solving the governing equations with segregated scheme. Governing equations of the present steady state simulations are solved in primitive form using the Semi-Implicit Method for Pressure-Linked Equations (SIMPLE) methodology since SIMPLE can only successfully predict steady state flow in the iterative procedure (Barton, 1997). At the final step of every iteration the velocity field and pressure distribution are corrected and updated to reach convergence as described by Patankar (1989). Momentum, turbulent kinetic energy and turbulent kinetic energy dissipation rate were discretized by first order upwind scheme.

\section{RESULTS AND DISCUSSION}

This section gives a successful comparison of the present numerical study with an available published experimental data and main findings obtained from a series of simulations straight and raised upper walls for $\mathrm{ER}=1.12$.

\subsection{Validation}

The present numerical solution has been compared with the experimental data of Driver and Seegmiller (1985). For validation of the present numerical work the analyses were considered under the conditions reported by Driver and Seegmiller (1985). Using the flow conditions of Driver and Seegmiller (1985), the comparisons have been made on the basis of the $\operatorname{Re}=38,000$ at $x / h=1,5,10$ and 20. As it can be observed both results are in good agreement (Fig.5) except some points. For instance at $\mathrm{x} / \mathrm{h}=1$ and $\mathrm{y} / \mathrm{h}=1$ the velocity values obtained from the present numerical study are higher than experimental data. Beneath $\mathrm{y} / \mathrm{h}=1$ a recirculation region occurs and over that velocity values become positive. At $\mathrm{y} / \mathrm{h}=1 \sim 3$ velocity profile recovers its original shape but it is seen there are some discrepancies between the present numerical study and experiment which shows the lack of employed RANS model at that region.

Fig.6 gives the skin friction distributions downstream of the step. It can be seen that the general trend is well captured. The good matching of two comparisons signifies the present computational scheme as applicable for the flow over backward-facing step.

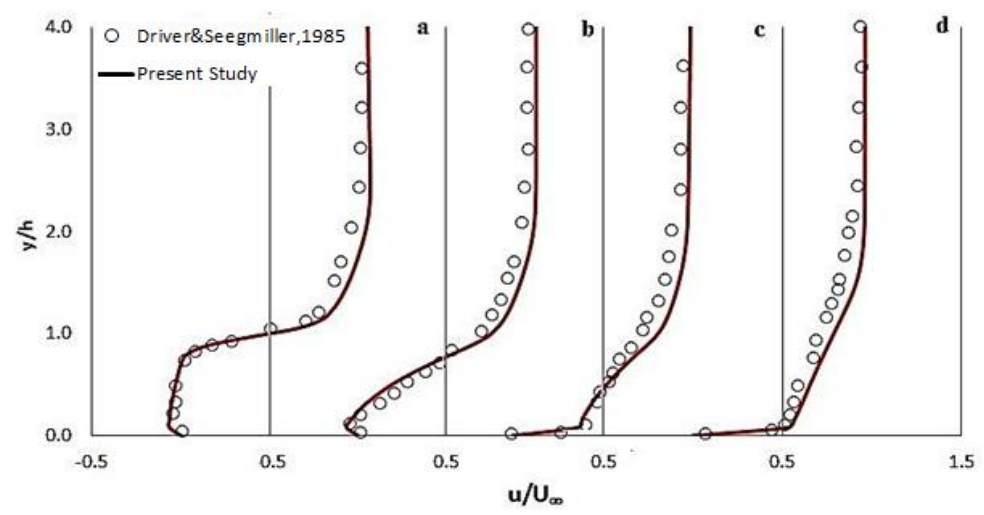

Fig. 5. Comparison of the present study with experimental data of Driver and Seegmiller, 1985 at a) $x / h=1, b)$ $\mathrm{x} / \mathrm{h}=5, \mathrm{c}) \mathrm{x} / \mathrm{h}=10$ and $\mathrm{d}) \mathrm{x} / \mathrm{h}=20$

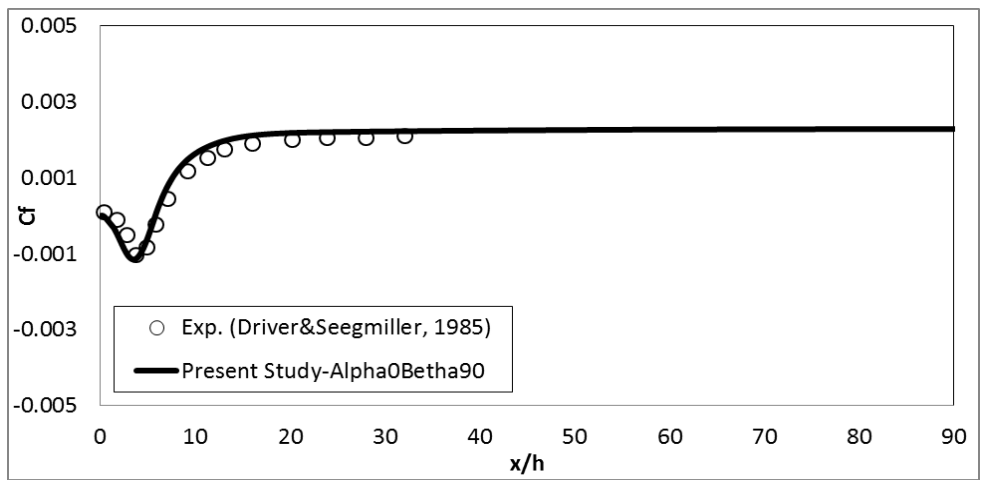

Fig. 6. Comparison of skin friction coefficient with the experimental data of Driver $\&$ Seegmiller, 1985 at $\alpha=0^{\circ}$, $\beta=90^{\circ}$ 


\subsection{Simulation Results}

As mentioned in Introduction section, after the backward-facing step flow reverses due to adverse pressure gradients. Therefore, a negative velocity region forms as shown in Fig. 7.

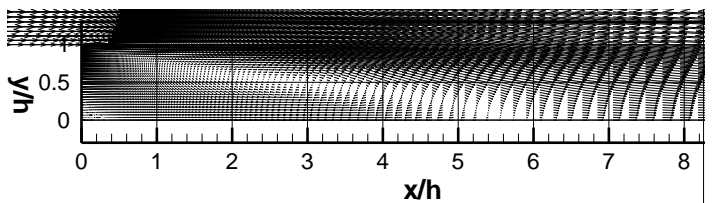

Fig. 7. Velocity vectors shows the reversed flow for $\alpha=0^{\circ}$ and $\beta=90^{\circ}$
Effects of step inclination angle on the velocity profile variations at $x / h=1,5,10,20,40$ and 50 have been shown in Fig.8. It is clear that changing the step inclination angles does not affect the velocity profile while the upper wall is parallel to the bottom wall. This also is valid for the first four streamwise stations when upper wall has been raised $6^{\circ}$.

It can be concluded that from $x / h=40$ step inclination angles affects the velocity profile. When upper wall has been raised $6^{\circ}$ lower inclination angles lead lower velocity values near the step and higher values at the vicinity of the raised wall (Fig.9).

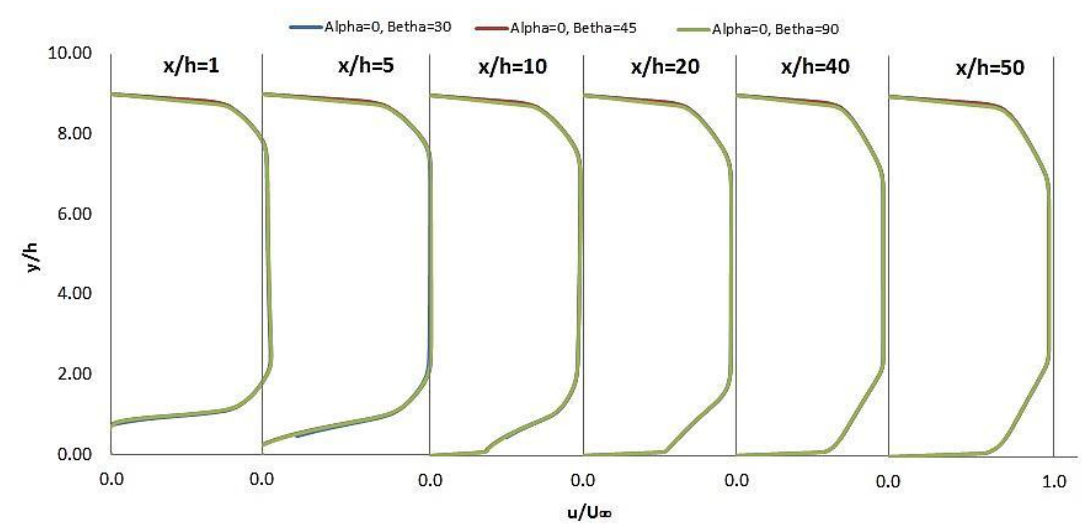

Fig. 8. Effects of step inclination angles on the velocity profile at different stations for $\alpha=0^{\circ}$

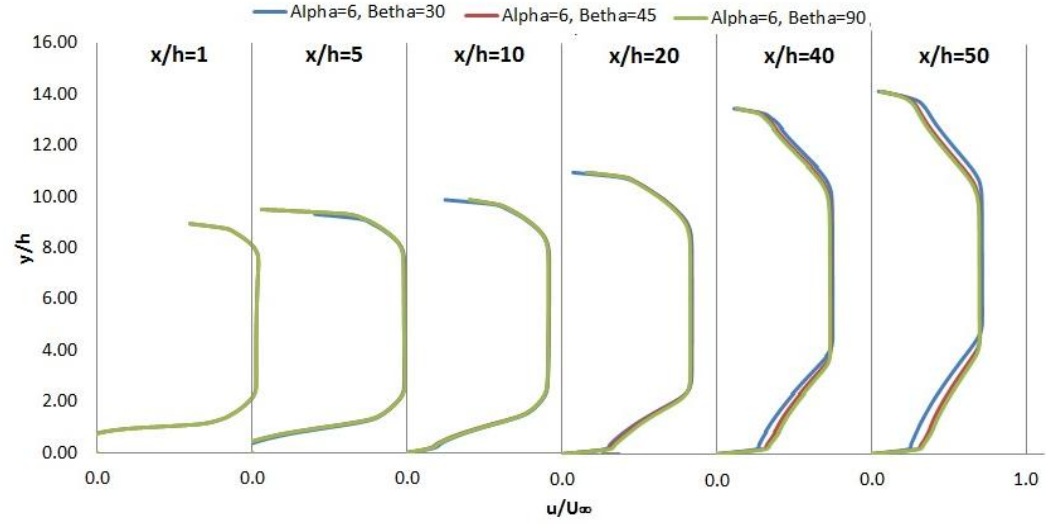

Fig. 9. Effects of step inclination angles on velocity profile at different stations for $\alpha=6^{\circ}$

Fig.10 shows that v-velocity values differs from each other's at the first $(x / h=1)$ and the second streamwise stations $(x / h=5)$ for $\alpha=0^{\circ}$ while all inclination angles give similar results at the remaining stations $(x / h=10$, $20,40,50)$.

The streamwise velocity profiles demonstrate the growth of the shear layer by entrainment of fluid and its subsequent contact with the all at the reattachment point while wall-normal velocity profiles implying the shear layer is bending toward the wall. As shown in Fig.10 downstream of the reattachment, the wall normal velocity is small that shows the development of a wall-bounded flow as proposed by Avancha and Pletcher (2002). At $\mathrm{x} / \mathrm{h}=10$ and at the subsequent stations wall-normal velocity are almost zero. 


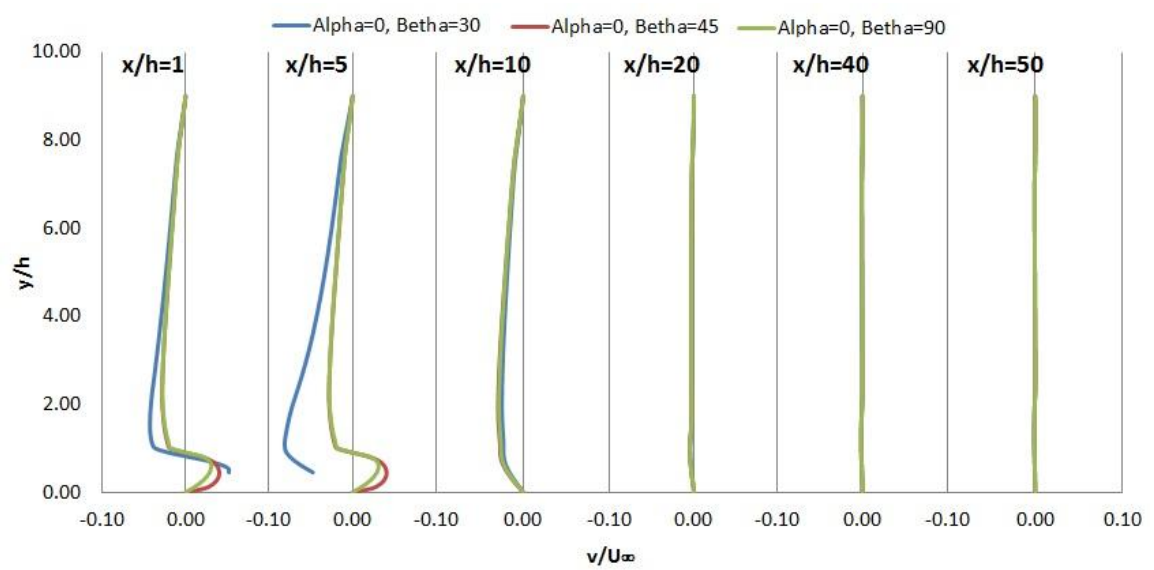

Fig. 10. Effects of opposite wall inclination angles on the normal velocity component at different streamwise stations for $\alpha=0^{\circ}$

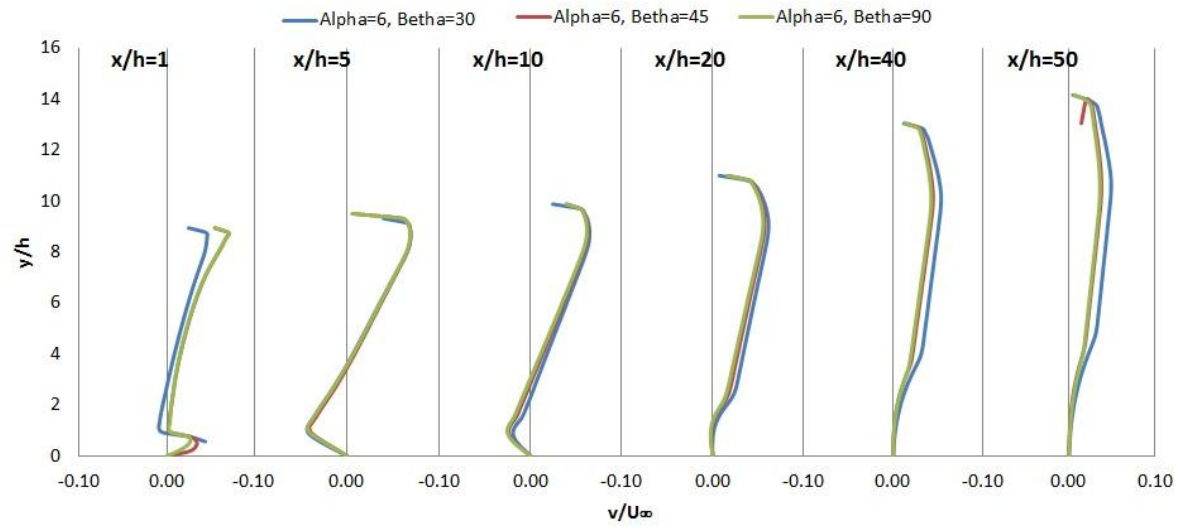

Fig. 11. Effects of upper wall inclination angles on the normal velocity component at different streamwise stations for $\alpha=6^{\circ}$

The effects of raised upper on the v-velocity component are shown in Fig.11 that reveals the change of velocity profile after the second station. It can be seen that step inclination angle of $\beta=30^{\circ}$ leads higher velocity values while $\beta=90^{\circ}$ is the lowest. For $\alpha=6^{\circ}$ v-velocity component (wall-normal velocity) shows different character than the case of $\alpha=0^{\circ}$. As it can be drawn the shear layer is bending toward the upper wall, as well.

Turbulence kinetic energy variations are shown in Fig.12 and Fig.13 for straight $\left(\alpha=0^{\circ}\right)$ and raised $\left(\alpha=6^{\circ}\right)$ upper walls, respectively.

It should be noted that two cases $\left(\alpha=0^{\circ}\right.$ and $\left.\alpha=6^{\circ}\right)$ shows similar $k$ distributions at the first three stations. For straight and raised upper wall the maximum value of $k$ is seen at $x / h=5$ that consistent with the results of
Kasagi and Matsunaga (1995) while they reported that maximum kinetic energy occurs at $x / h=4.5$.

When the upper wall raised $6^{\circ}$ the kinetic energy profiles change especially at the bottom wall for all three step inclination angles. Comparing to $\alpha=0^{\circ}, k$ values near upper and bottom walls increase at $x / h=20,40$ and 50 and decrease for the first three stations at $\alpha=6^{\circ}$.

It can be seen that $\beta=30^{\circ}$ generates the highest turbulence kinetic energy at the first station for both $\alpha=0^{\circ}$ and $\alpha=6^{\circ}$. After that station $k$ values get closer at the subsequent points at $\alpha=0^{\circ}$. From the kinetic energy variation comparisons it can be concluded that raising the upper wall leads the flow to be more turbulent especially at the lower step inclination angles. 
S. Bayraktar / JAFM, Vol. 7, No. 1, pp. 155-167, 2014.

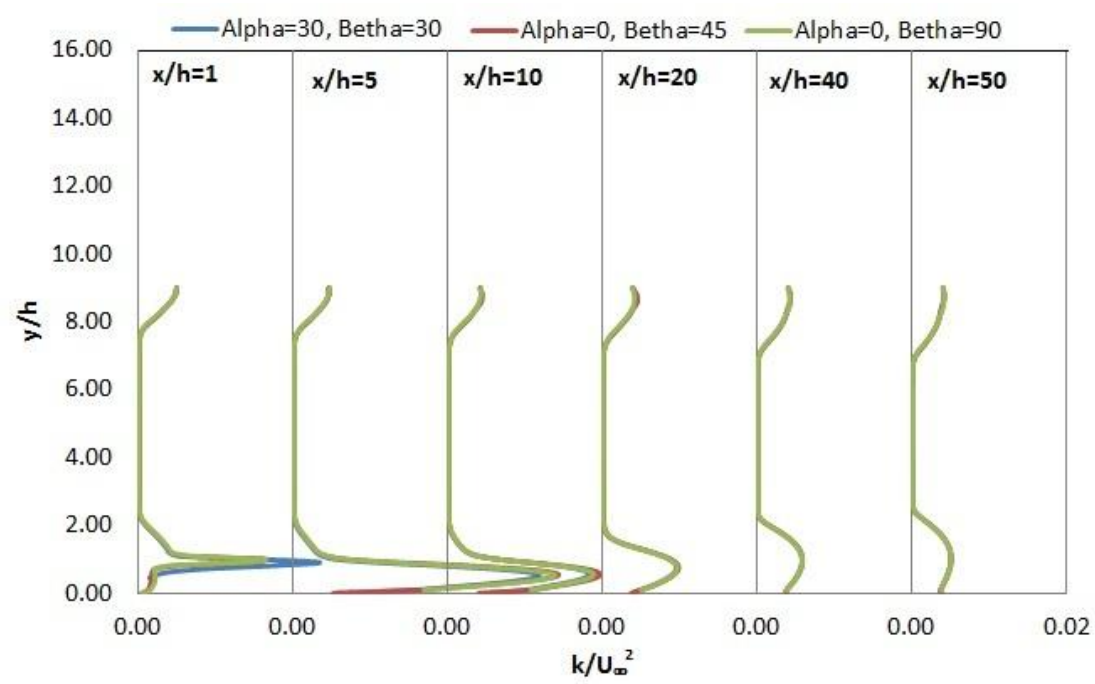

Fig. 12. Effects of step inclination angles on the turbulent kinetic energy variations at different streamwise stations for $\alpha=0^{\circ}$

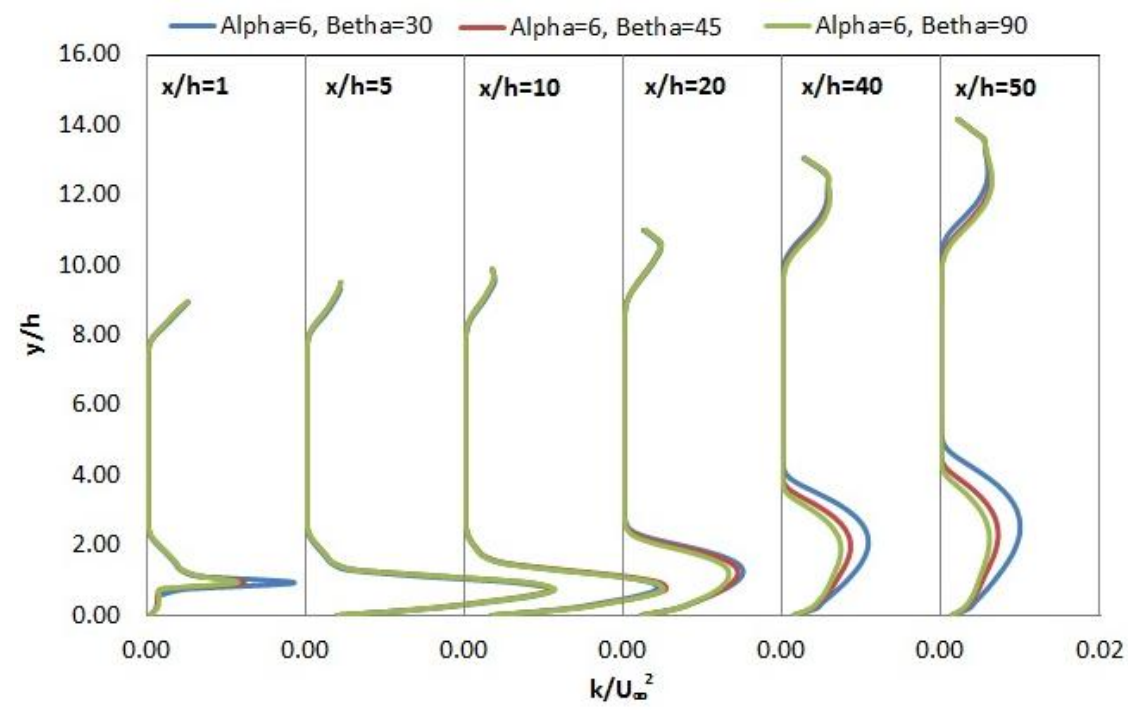

Fig. 13. Effects of step inclination angles on the turbulent kinetic energy variations at different streamwise stations for $\alpha=6^{\circ}$

Abu-Mulaweh (2003) reported that only one separated region develops downstream of the step. Meanwhile, one or two regions might develop with the one upstream and the other downstream from the step. Fig.14 shows only two recirculation regions after the step. The smaller one occurs at the region between $0<$ $x / h<-0.2$ and $0<y / h<0.1$ while the bigger occupies the region just the downstream of the step. The flow separates after step and reattaches the bottom wall at $x / h=5.8$ which indicates the reattachment length $\left(X_{R} / h\right)$. Although not shown here, it is observed that this smaller region does not occur when step inclination angles are smaller than $90^{\circ}$.

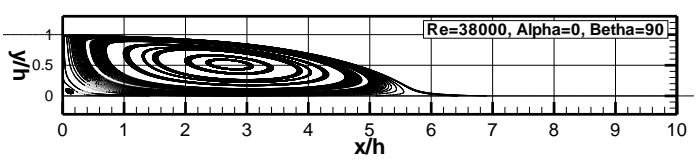

Fig. 14. Streamlines that show the circulation regions and reattachment length for $\alpha=0^{\circ}, \beta=90^{\circ}$ at $\operatorname{Re}=38,000$

The reattachment length variations with Re numbers and step inclination angle are shown in Fig.15 for revealing the effects of upper wall angle. It is realized that raising the upper wall leads the bigger 
reattachment lengths. The size of the reattachment length is bigger at all step inclination angles when the upper wall rises $6^{\circ}$. As mentioned in the previous sections the effects of Re number on the reattachment length were investigated by many researchers in the past. Erturk (2008) showed that the size of the recirculation regions grows almost linearly as $\mathrm{Re}$ number increases up to 3,000. It was emphasized that at low Re numbers the reattachment length increases linearly (Barton, 1995). On the other hand, it is seen from Fig. 15 that for $\operatorname{Re}>15,000$ this is not valid any longer. Fig. 15 shows the reattachment length slightly increases with the $\operatorname{Re}$ numbers at $\beta=0^{\circ}$ while step inclination angle kept constant at $\alpha=30^{\circ}$ and $90^{\circ}$. At the step inclination angle of $45^{\circ}$ the reattachment length is almost constant and does not change with Re numbers. The biggest reattachment length occurs at the highest step inclination angle $\left(\alpha=90^{\circ}\right)$ while the smallest one forms at $\alpha=30^{\circ}$.

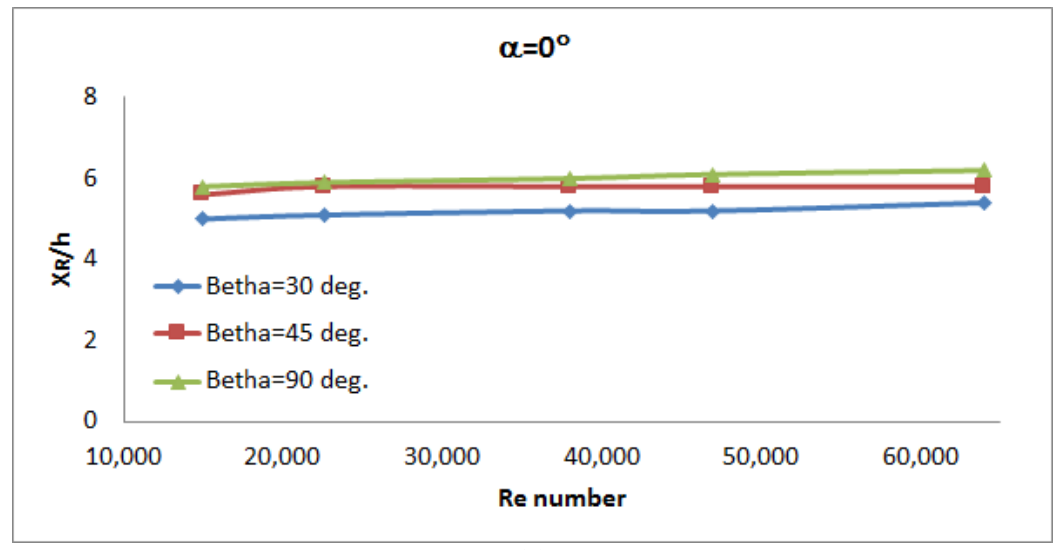

(a)

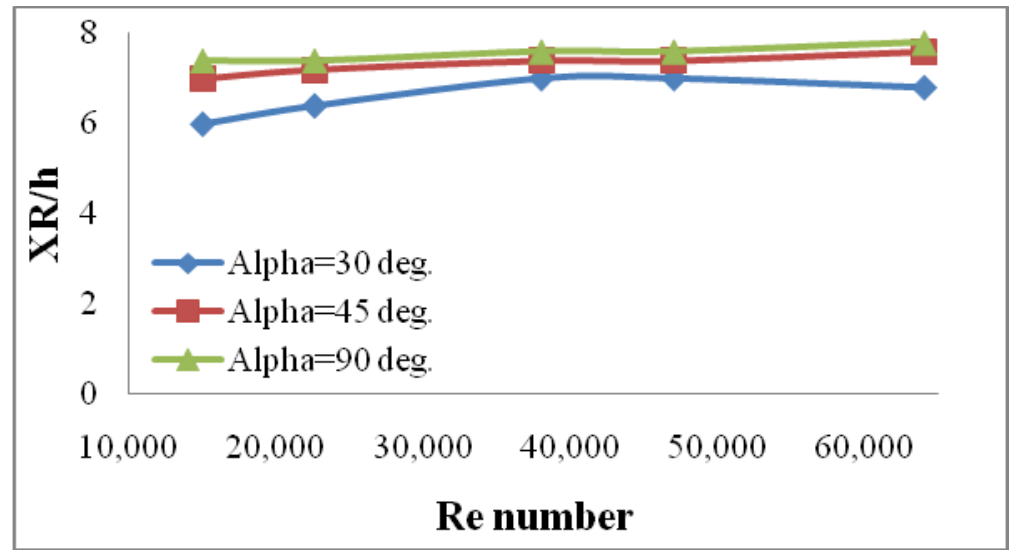

(b)

Fig. 15. Reattachment length variation at step angle a) $\alpha=0^{\circ}$ and b) $\alpha=6^{\circ}$ as a function of Re numbers

According to Ruck and Makiola (1993) this indicates that the spreading of the free shear layer is damped for step angles smaller than $90^{\circ}$ due to the presence of the nearer coming step wall. The similar correlation can be seen at $\beta=6^{\circ}$. Unlike the case of $\beta=0^{\circ}$ (straight upper wall) the reattachment length of $\alpha=30^{\circ}$ decreases after $\operatorname{Re}=47,000$. It should be noted that the reattachment lengths presented here are shorter than that of Singh et al. (2011) and Ahn et al. (1997). Both works have been carried out at $E R=1.48$ while the present study has been conducted at $E R=1.12$. The similar conclusion can be drawn from Ruck and Makiola (1993) who investigated the flow over backward-facing step with straight upper wall for different step inclination angle at $\mathrm{ER}=1.48,2.0$ and 3.27. As it was suggested by Armaly et al. (1983) as the ER decreases, a lower reattachment length to stepheight-ratio, $X_{R} / h$, is obtained. This is one of the reasons of discrepancy with the reported results in the past. In addition to that, although Realizable $\mathrm{k}-\varepsilon$ turbulence model are in good agreement with the experimental data it is inadequate to catch the exact value of reattachment length at high Re numbers. 


\section{Conclusion}

The present numerical study reveals the effects of the raised upper wall on velocity, turbulence kinetic energy and reattachment length for various $\mathrm{Re}$ numbers ranging 15,000 to 64,000 . The effects of step inclination angle are also investigated and compared with the available published data. It is seen that the turbulence kinetic energy increases after the step and reaches its maximum at $x / h=5$ for both straight and raised upper wall. The reattachment length stays constant while Re number increases. Large step inclination angles produce longer reattachment lengths. It can be concluded from the comparison with the findings of the present and the published works that the ER affects the size of recirculation region and the length of the reattachment point. The smaller ER leads the smaller reattachment lengths.

\section{REFERENCES}

Abu-Mulaweh, H.I. (2003). A review of research on laminar mixed convection flow over backwardand forward-facing steps, International journal of Thermal Sciences, 42, 897-909.

Abu-Mulaweh, H.I., T.S. Chen and B.F. Armaly (2002). Turbulent mixed convection flow over a backward-facing step-the effect of the step height, International Journal of Heat and Fluid Flow, 23, 758-765.

Addad, Y., D. Laurence, C. Talotte and M.C. Jacob (2003). Large eddy simulation of a forwardbackward facing step for acoustic source identification, International Journal of Heat and Fluid Flow, 24, 562-571.

Ahn, J.W., T.S. Park and H.J. Sung (1997). Application of a near-wall turbulence model to the flows over a step with inclined wall, International Journal of Heat and Fluid Flow, 18, 209-217.

Armaly, B.F., F. Durst and J.C.F. Pereira (1983). Experimental and theoretical investigation of backward-facing step, Journal of Fluid Mechanics, 127, 473-496.

Avancha, R.V.R. and R. Pletcher (2002). Large eddy simulation of the turbulent flow past a backwardfacing step with heat transfer and property variations, International Journal of Heat and Fluid Flow, 23, 601-614.
Barkley, D., M.G.M. Gomes and R.D. Henderson (2002). Three-dimensional instability in flow over a backward-facing step, Journal of Fluid Mechanics, 473, 167-190.

Barton, I.E., (1997). Laminar flow over a backwardfacing step with a stream of hot particles, International Journal of Heat and Fluid Flow, $18,400-410$.

Barton, I.E. (1955). Computation of particle tracks over a backward-facing step, Journal of Aerosol Science, 26(6), 887-901.

Blackburn, H.M., D. Barkley and S.J. Sherwin (2008). Convective instability and transient growth in flow over a backward-facing step, Journal of Fluid Mechanics, 603, 271-304.

Bouda, N.N., R. Schiestel, M. Amielh, C. Rey and T. Benabid (2008). Experimental approach and numerical prediction of a turbulent wall jet over a backward-facing step, International Journal of Heat and Fluid Flow, 29, 927-944.

Bouterra, M., Z. Mehrez, A.E. Cafsi, A. Belghith and P.L. Quere (2011). Control of local mass transfer in the separated and reattaching flow by a periodic forcing, Journal of Applied Fluid Mechanics, 4(1), 63-67.

Brederode, V. and P. Bradshaw (1972). Threedimensional flow in in nominally twodimensional separation bubbles, Imperial College of Science and Technology, Technical Aero Report, No.72-19.

Chen, Y.T., J.H. Nie, B.F. Armaly and H.T. Hsieh (2006). Turbulent separated convection flow adjacent to backward-facing step-effects of step height, International Journal of Heat and Mass Transfer, 49, 3670-3680.

Chiang, T.P., T.W.H. Sheu and C.C. Fang (1999). Numerical investigation of vortical evolution in a backward-facing step expansion flow, Applied Mathematical modeling, 23, 915-932.

Cruchaga, M.A. (1998). A Study of the backwardfacing step problem using a generalized streamline formulation, Communications in numerical methods in engineering, 14, 697-708. 
S. Bayraktar / JAFM, Vol. 7, No. 1, pp. 155-167, 2014.

Driver, D.M. and H.L. Seegmiller (1985). Features of a Reattaching Turbulent Shear Layer in Divergent Channel Flow, AIAA Journal, 23, 163.

Erturk, E. (2008). Numerical solutions of 2-D steady incompressible flow over a backward-facing step, Part I: High Reynolds number solutions, Computer \& Fluids, 37, 633-655.

Kasagi, N. and A. Matsunaga (1995). Threedimensional particle-tracking velocimetry measurement of turbulence statistics and energy budget in a backward-facing step flow, International Journal of Heat and Fluid Flow, $16,477-485$.

Kim, J.Y., A.J. Ghajar, C. Tang and G.L. Foutch (2005). Comparison of near-wall treatment methods for high Reynolds number backwardfacing step flow, International Journal of Computational Fluid Dynamics, 19(7), 493-500.

Lan, H., B.F. Armaly and J.A. Drallmeier (2009). Three-dimensional simulation of turbulent forced convection in a duct with backward-facing step, International Journal of Heat and Mass Transfer, 52, 1690-1700.

Lanzerstorfer, D. and H.C. Kuhlmann (2012). Global stability of the two-dimensional flow over a backward-facing step, Journal of Fluid Mechanics, 693, 1-27.

Le, H., P. Moin and J. Kim (1997). Direct numerical simulation of turbulent flow over backwardfacing step, Journal of Fluid Mechanics, 330, 349-374.

Mehrez, Z., M. Bouterra, A.E. Cafsi, A. Belghith and P.L. Quere (2010). Simulation of the periodically perturbed separated and reattaching flow over a backward-facing step, Journal of Applied Fluid Mechanics, 3(2), 1-8,

Papadopoulos, G. and M.V. Otugen (1995). Separation and reattachment flow structure in a suddenly expanding rectangular duct, ASME Journal of Fluids Engineering, 117, 17-23.

Patankar, S.V. (1980). Numerical heat transfer and fluid flow, Taylor and Francis, Philadelphia.
Piirto, M., P. Saarenrinne and H. Eloranta (2002). Turbulence control with particle image velocimetry in a backward-facing step, Journal of Fluids Engineering, 124, 1044-1052.

Rajabi, E. and M.R. Kavianpour (2012). Intelligent prediction of turbulent flow over backwardfacing step using direct numerical simulation data, Engineering Applications of Computational Fluid Mechanics, 6(4), 490-503.

Rouizi, Y., Y. Favennec, J. Ventura and D. Petit (2009). Numerical model reduction of 2D steady incompressible laminar flows: Application on the flow over a backward-facing step, Journal of Computational Physics, 228, 2239-2255.

Ruck, B. and B. Makiola. Flow Separation over the inclined Step, Near-Wall Turbulent Flows (R.M.C., So, C.G., Speziale, B.E. Launder, eds.) Elsevier, p.999.

Saldana, J.G.B., P.Q. Diez, F.S. Silva and I.C. Mariscal (2007). Numerical simulation for the flow structures following a three-dimensional horizontal forward-facing step channel, Revista Mexicana De Fisica, 53(2), 87-95.

Schafer, F., M. Breuer and F. Durst (2009). The dynamics of the transitional flow over a backward-facing step, Journal of Fluid Mechanics, 623, 85-119.

Sheu, T.W.H. and H.P. Rani (2006). Exploration of vortex dynamics for transitional flows in a threedimensional backward-facing step channel, Journal of Fluid Mechanics, 550, 61-83.

Singh, A.P., A.R. Paul and P. Ranjan (2001). Investigation of Reattachment length for a turbulent flow over a backward-facing step for different step angle, International Journal of Engineering, Science and Technology, 3, 2, 8488.

Spazzini, P.G., G. Luso, M. Onorato, N. Zurlo and G.M. Di Cicca (2001). Experiments in Fluids, 30, 551-561.

Stefano, G.D., F.M. Denaro and G. Riccardi (1998). Analysis of 3D backward-facing step incompressible flows via a local average-based 
S. Bayraktar / JAFM, Vol. 7, No. 1, pp. 155-167, 2014.

numerical procedure, International Journal for Numerical Methods in Fluids, 28, 1073-1091.

Terhaar, S., A. Velazquez, J.R. Arias and M. SanchezSanz (2010). Experimental study on the unsteady laminar heat transfer downstream of a backwards-facing step, International Communications in Heat and Mass Transfer, 37, 457-462.

Williams, P.T. and A.J. Baker (1997). Numerical simulations of laminar flow over a 3D backwardfacing step, International Journal for Numerical Methods in Fluids, 24, 1159-1183.
Yoshioka, S., S. Obi, and S. Masuda (2001). Turbulence statistics of periodically perturbed separated flow over backward-facing step, International Journal of Heat and Fluid Flow, 22, 393-401.

Yu, K.F., K.S. Lau and C.K. Chan (2004). Numerical simulation of gas-particle flow in a single-sided backward-facing step, Journal of Computational and Applied Mathematics, 163, 319-331. 